\title{
Control Topology Options for Single-Phase UPS Inverters
}

\author{
Michael J. Ryan, William E. Brumsickle, and Robert D. Lorenz, Senior Member, IEEE
}

\begin{abstract}
Four control topologies for single-phase uninterruptible power system (UPS) inverters are presented and compared, with the common objective of providing a dynamically stiff, low total harmonic distortion (THD), sinusoidal output voltage. Full-state feedback, full-state command controllers are shown, utilizing both filter inductor current and filter capacitor current feedback to augment output voltage control. All controllers presented include output voltage decoupling in a manner analogous to "back-electromotive force (EMF)" decoupling in dc motor drives. Disturbance input decoupling of the load current and its derivative is presented. An observer-based controller is additionally considered and is shown to be a technically viable, economically attractive option. The accuracy transfer function of the observer estimate is used to evaluate its measurement performance. Comparative disturbance rejection is evaluated by overlaying the dynamic stiffness (inverse of output impedance) frequency response of each controller on a single plot. Experimental results for one controller are presented.
\end{abstract}

Index Terms- Control systems, dc-ac power conversion, impedance, inverters, observers, state space methods, state estimation, transient analysis, voltage control.

\section{INTRODUCTION}

$\mathbf{I}$ $\mathrm{N}$ all uninterruptible power system (UPS)-style inverters the goal is to maintain the desired output voltage waveform over all loading conditions and transients. In the past, sinewave inverters relied on open-loop feedforward control to produce the shape of the waveform, while a relatively slow output voltage rms feedback loop regulated the magnitude. While these types of controllers could maintain a desired steady-state rms output voltage, their response to step changes in load were noticeably slow (several cycles of the output waveform), and nonlinear loads could greatly distort their output voltage waveform. Today, various modern feedback control techniques are available to control the output voltage waveform continuously, rather than on an rms basis. These so-called "instantaneous" controllers offer many performance advantages including faster (sub-cycle) transient response, better total harmonic distortion (THD), and improved disturbance rejection via lower output impedance.

Paper IPCSD 96-48, approved by the Industrial Power Converter Committee of the IEEE Industry Applications Society for presentation at the 1996 International Conference on Power Electronics, Drives and Energy Systems for Industrial Growth (PEDES), New Delhi, India, January 8-11. This work was supported by the Wisconsin Electric Machines and Power Electronics Consortium (WEMPEC), University of Wisconsin, Madison. Manuscript released for publication September 3, 1996.

The authors are with the Department of Electrical and Computer Engineering, University of Wisconsin, Madison, WI 53706 USA.

Publisher Item Identifier S 0093-9994(97)01539-9.
Many instantaneous controllers have been presented in the literature that actively control the inverter's output over the entire waveform. Digital controllers incorporating various forms of state feedback have shown good performance, but at the cost of a relatively fast $\mu$-processor which must compute inverter duty cycle on a pulse-by-pulse basis [3], [6], [10]. Several hysteresis-type controllers have been presented in [9] and [12]. These controllers can suffer from relatively high and variable switching frequencies. Analogbased controllers utilizing inductor current feedback are found in [4], [7], and [11], while capacitor current feedback topologies are found in [1], [2], [5], [8], and [10]. The technique of dc bus voltage decoupling has been shown in [1] and [8], and the advantages of output voltage, or "backelectromotive force (EMF)" decoupling have been presented in [1]. The importance of the inverter's closed-loop output impedance characteristic has been recognized in [1], [4], and [6].

This paper will present several state-space control topology options for a single-phase PWM inverter with an $L C$ output filter. Two basic feedback topologies are explored: 1) filter inductor and load current sensing and 2) filter capacitor current sensing, where both approaches use a full-state command structure. For the case of inductor current feedback, two methods of load current decoupling will be considered. In the case of capacitor current feedback, a Luenberger-style observer for capacitor current will also be considered in lieu of a current sensor. All controllers presented employ active decoupling of both the dc bus and the "back-EMF" of the output voltage. The output dynamic stiffness (inverse of output impedance) of each controller is evaluated and compared on a single plot. Experimental results are presented for the capacitor current feedback controller topology.

\section{SINEWAVE INVERTER COMPONENTS AND STATE-SPACE MODEL}

Sinewave inverters are typified by the components shown in Fig. 1. At the heart of the system is a full-bridge inverter which modulates a dc bus into a cycle-by-cycle average output voltage, $e_{i}$.

The amplitude of $e_{i}$ is directly proportional to the commanded duty cycle of the inverter, which varies over $\pm 100 \%$, and the amplitude of the dc bus voltage, $V_{\mathrm{dc}}$. Thus, $e_{i}$ can range from $+V_{\mathrm{dc}}$ to $-V_{\mathrm{dc}}$.

The output of the inverter is in turn passed through a second-order $L C$ filter to block all but the desired fundamental 


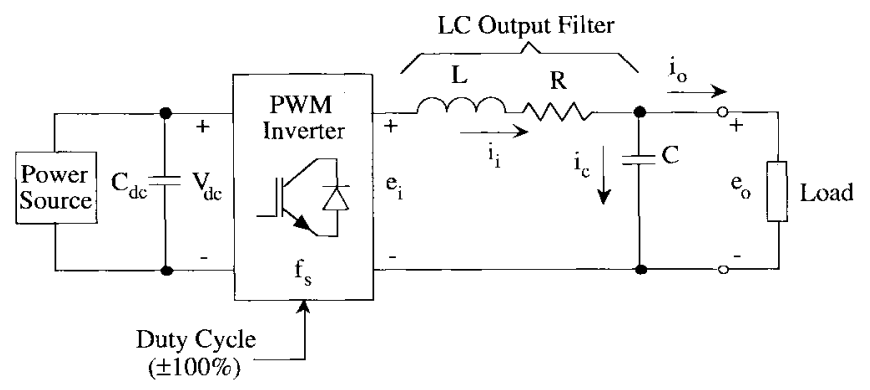

Fig. 1. Single-phase UPS inverter system.

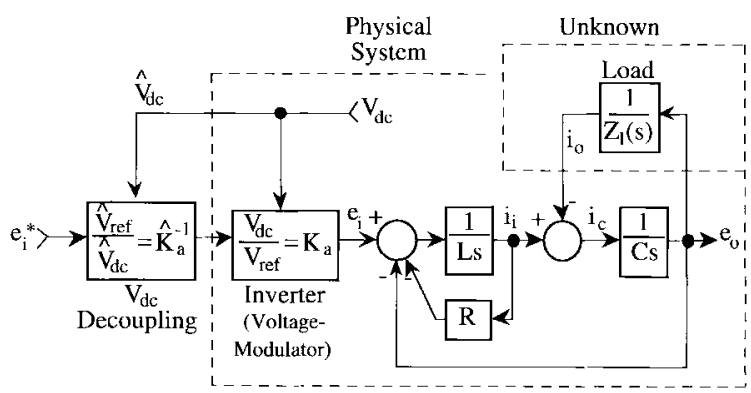

Fig. 2. State-space model with dc bus voltage decoupling.

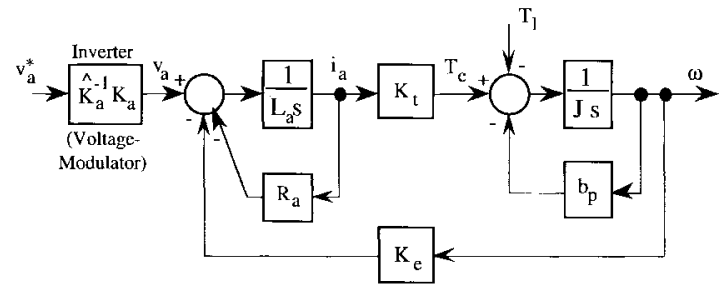

Fig. 3. Analogous state-space dc motor system diagram.

frequency $(50 / 60 / 400 \mathrm{~Hz})$. The resistance of the output filter inductor is represented by $R$. Filter capacitor ESR is ignored since the break frequency (typically above $200 \mathrm{kHz}$ ) appears far above the range of concern. The load shown in Fig. 1 can be any type of ac load: resistive, inductive, capacitive, or nonlinear.

The power source shown in Fig. 1 can be of variable voltage (such as a battery) which will tend to "droop" under heavy loads. Fig. 2 shows a state-space model of the system with $V_{\mathrm{dc}}$ decoupling to compensate for changes in the bus voltage; permitting $e_{i}$ to be commanded directly. The carets, ^, denote estimated values such as $\hat{e}_{O}$.

Because the switching frequency, $f_{s}$, of the inverter is usually several orders of magnitude above the fundamental, the dynamics of the inverter are usually ignored. The $V_{\mathrm{dc}}$ compensated inverter is thus depicted as a simple unity gain block in all subsequent diagrams.

In studying the physical system depicted in Fig. 2, it was noted that the $L C$ filter was directly analogous to a de motor model, as shown in Fig. 3, where $K_{e}=K_{t}=1$, and $b_{p}=0$. The filter capacitance is analogous to rotor inertia. Thus, all of the advanced dc motor control techniques previously developed can be applied directly to the control of the inverter and $L C$ filter.

\section{FILTER InDUCTOR CURRENT REGULATOR}

If inductor current is controlled, it becomes possible to implement various forms of disturbance input decoupling (which is also known as disturbance feedforward control).

\section{A. Load Current Decoupling}

If it is economically feasible to measure the load current, then it can readily be decoupled. Fig. 4 shows a full-state feedback controller with load current (disturbance input) decoupling, where time derivatives are indicated by "•" and commanded values are indicated by "*," such as $\dot{e}_{0}^{*}$. The controller is shown in a cascade format, with an inner inductor current loop and an outer output voltage loop. The controller additionally uses full-state command feedforward and state feedback decoupling of the output voltage and filter inductor $I R$ drop. Note that with the state feedback decoupling terms, the remaining control inputs command voltage across the filter inductor, $e_{L}^{*}$, directly. Nulling the state coupling in this manner allows a simple proportional gain, $R_{a}$, to be used in forming the inductor current loop.

The disturbance input decoupling is implemented by sensing the load current, $i_{o}$, and using it as an additional current loop command to produce the needed load current without waiting for errors in voltage to occur. This leaves only the capacitor current to be commanded, $i_{c}^{*}=\dot{e}_{o}^{*} \hat{C}$, which is independent of load current. Thus, load transients can be effectively rejected up to the bandwidth of the inductor current loop. This bandwidth (set by $R_{a}$ ) can be as high as $1 / 5-1 / 4$ of $f_{s}$. If the bandwidth were infinite, the disturbance input decoupling would be perfect, and the dynamic stiffness (defined in Section V) would be infinite.

As shown in Fig. $4, \ddot{e}_{0}^{*}$ is used to give a full command vector, though in practice (for a $50-$ or $60-\mathrm{Hz}$ command) the relative magnitudes of $L$ and $C$ will render $e_{i-c f f}$ to approximately $1 / 1000$ th of the total $e_{i}^{*}$ command. Thus, the majority of $e_{i}^{*}$ is actually determined by the $e_{0}$ decoupling state feedback. This may be explained by recognizing that the fundamental voltage drop across $L$ is quite small when compared to $e_{0}$. From Fig. 4, the command response transfer function is found as

$$
\frac{e_{o}}{e_{o}^{*}}=\frac{\hat{C} \hat{L} s^{3}+\hat{C} R_{a} s^{2}+R_{a} K_{v} s+R_{a} K_{i}}{C L s^{3}+C R_{a} s^{2}+R_{a} K_{v} s+R_{a} K_{i}} .
$$

If the estimated parameters $\hat{L}, \hat{R}$, and $\hat{C}$ are accurate, the controller will exhibit perfect command tracking up to the bandwidth limit of the voltage modulator. Since $f_{s}$ is usually several orders of magnitude above the fundamental, this does not pose a limit. From Fig. 4, the output dynamic stiffness is found as

$$
\frac{i_{o}}{e_{o}}=\frac{C L s^{3}+C R_{a} s^{2}+R_{a} K_{v} s+R_{a} K_{i}}{L s^{2}} .
$$

This is plotted in Fig. 8, along with the dynamic stiffness of the other controllers for comparison. Table II lists the controller gains and the eigenvalues used for all the controller alternatives. 


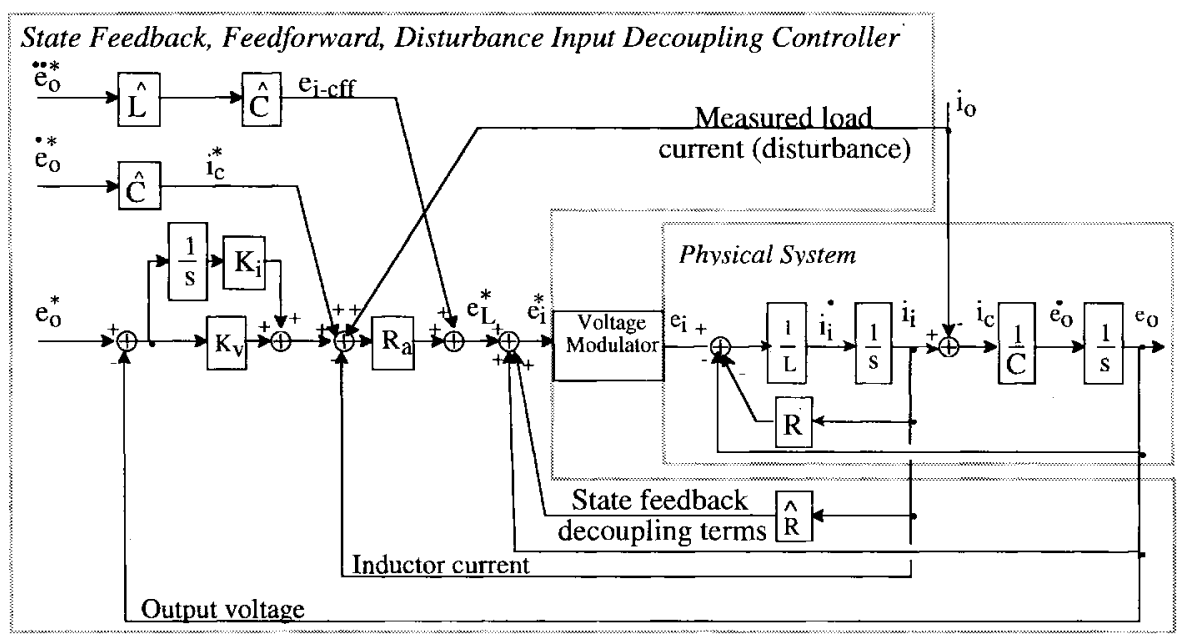

Fig. 4. State feedback controller with state command feedforward, decoupling state feedback, and disturbance input decoupling via load current sensing.

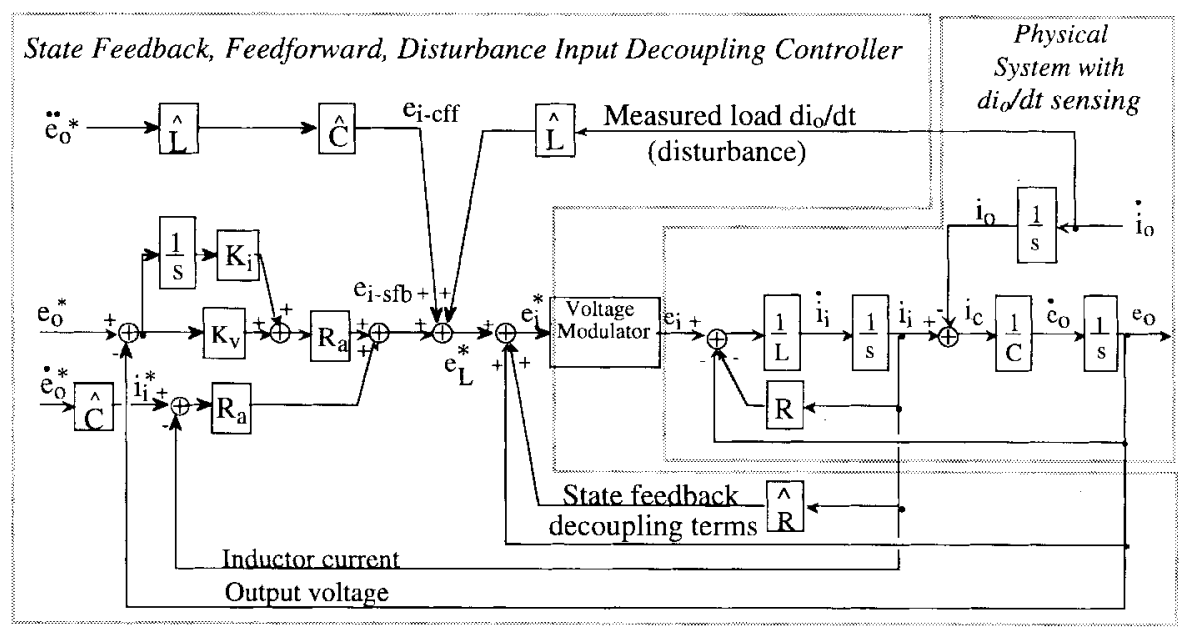

Fig. 5. State feedback controller with state command feedforward, decoupling state feedback, and disturbance input decoupling via load current $d i_{\circ} / d t$ sensing.

\section{B. Load Current Decoupling With di $i_{o} / d t$ Feedback}

An alternative approach to disturbance input decoupling which further improves the dynamic stiffness uses the derivative of the output current, $d i_{o} / d t=i_{o}$, which can be sensed with a small choke and fed back, as shown in Fig. 5. In conjunction with the output voltage and inductor resistance decoupling, the $d i_{o} / d t$ term can now be used to fully decouple load-induced voltage transients across the output filter inductance. Thus, the system will now exhibit infinite dynamic stiffness up to the bandwidth of the voltage modulator, provided that the estimate of inductance $\hat{L}$ is accurate; it should be noted that $\hat{L}$ may be mapped as a nonlinear function of $i_{0}$ to improve the parameter estimate.

This increased dynamic stiffness, and the likelihood that sensing $d i_{o} / d t$ with a small choke will be less expensive than a full current sensor for $i_{o}$, makes this an attractive control topology. As such, the topology in Fig. 5 is considered the "upper bound" of the controllers represented in this paper.

\section{Filter Capacitor CurRent Regulator}

If capacitor current is controlled, dynamic stiffness can be improved substantially. The key issue for capacitor current is how the sensing is performed, i.e., either via direct measurement or via an observer.

\section{A. Capacitor Current Sensed}

As an alternative to sensing inductor current and load current (or load $d i_{o} / d t$ ), the filter capacitor current, $i_{c}$, may be measured and used in a state feedback controller as shown in Fig. 6. It is especially relevant because the derivative of the output voltage, $\dot{e}_{o}$, is proportional to $i_{c}$. Because $i_{c}$ is small and ac in nature, it may be sensed with a small inexpensive current transformer. From a disturbance rejection point of view, capacitor current feedback directly senses changes in load current, as the capacitor current is the sum of inductor and load currents. Thus, without some form of disturbance input decoupling, as shown in Figs. 4 and 5, a capacitor current feedback topology will exhibit better dynamic stiffness than that of a controller with inductor current feedback alone. 


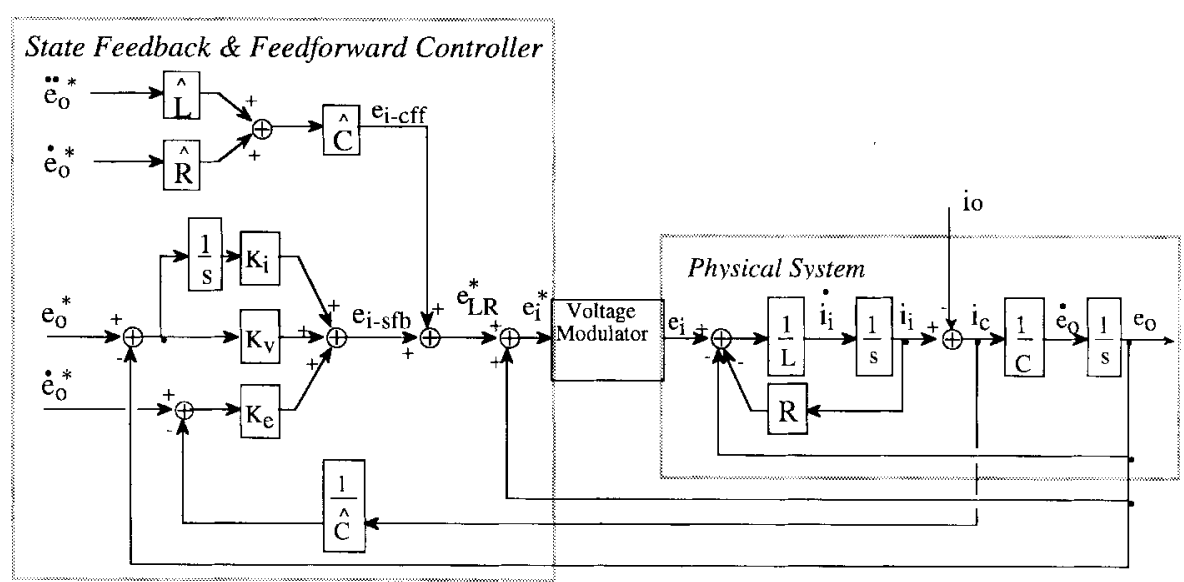

Fig. 6. State feedback controller based on capacitor current sensing with state command feedforward and output voltage decoupling state feedback.

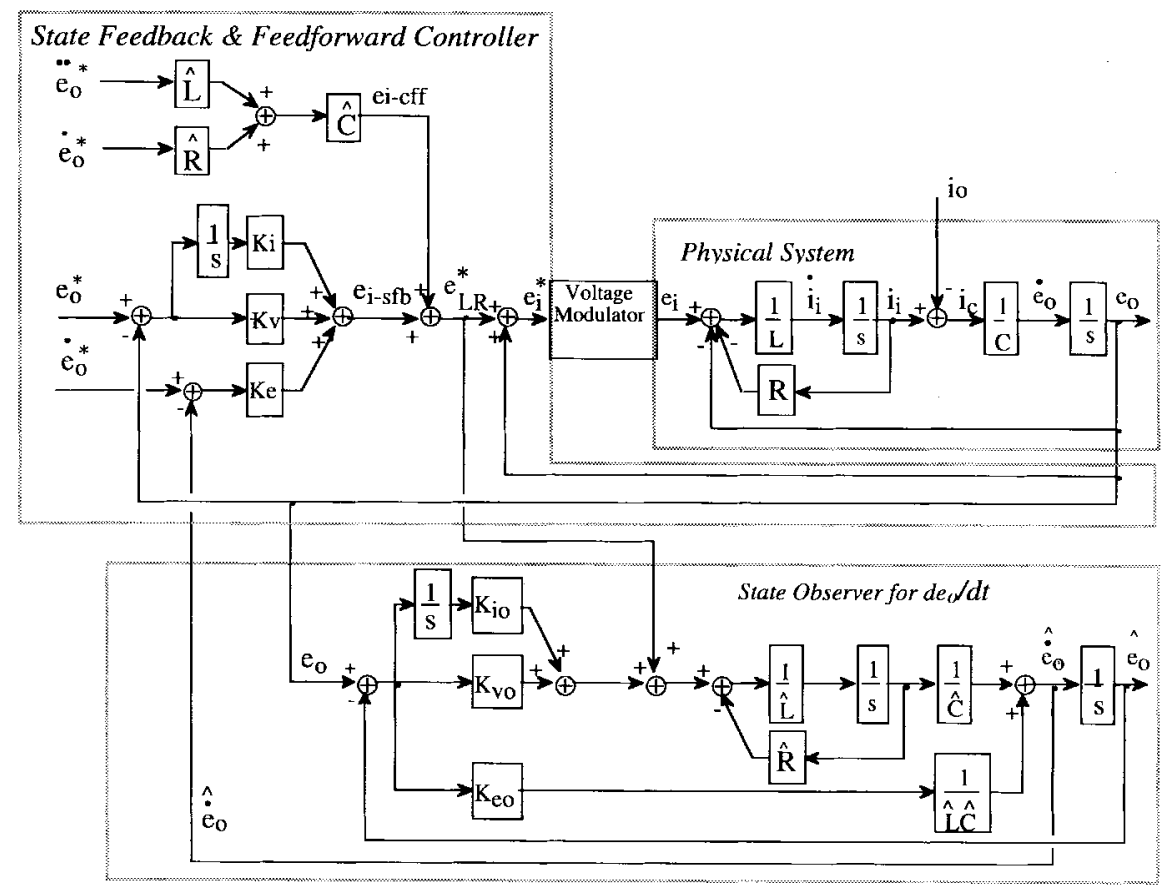

Fig. 7. Observer-based capacitor current feedback state-space controller.

The command response and dynamic stiffness transfer functions can be found as

and

$$
\frac{e_{o}}{e_{o}^{*}}=\frac{\hat{C} \hat{L} s^{3}+\left(\hat{C} \hat{R}+\hat{K}_{e}\right) s^{2}+K_{v} s+K_{i}}{C L s^{3}+\left(C R+K_{e}\right) s^{2}+K_{v} s+K_{i}}
$$

$$
\frac{i_{o}}{e_{o}}=\frac{C L s^{3}+\left(C R+K_{e}\right) s^{2}+K_{v} s+K_{i}}{L s^{2}+R s}
$$

respectively.

Because $i_{i}$ is not measured, the inductor resistance is not decoupled through state feedback, but rather through the feedforward control path. Because of this, the resistance affects the dynamic stiffness, in the form of a low break frequency, $R / L$. Again, the controller has perfect command tracking for all frequencies if the parameter estimates are correct. While the inductor resistance and nominal inductance may change significantly over temperature and loading, respectively, the capacitor value is usually quite stable. Fig. 8 depicts the dynamic stiffness frequency response and Table II lists the controller gains and eigenvalues used for all of the controller alternatives.

\section{B. Capacitor Current Feedback via Observer}

If only output voltage $e_{0}$ is measured. the derivative term, $\dot{e}_{o}$, may be estimated by an enhanced Luenberger observer. The Luenberger observer, introduced in [13] with design examples in [14]-[16], makes use of all available manipulated inputs as command feedforward information to allow the observer to track commanded inputs with the same response as the physical system. It also actively controls the error in its estimate of the measured physical state $e_{o}$ and so forces convergence of the estimated state, $\hat{\dot{e}}_{o}$, to the actual state value. An integration state is added to the observer controller to force 


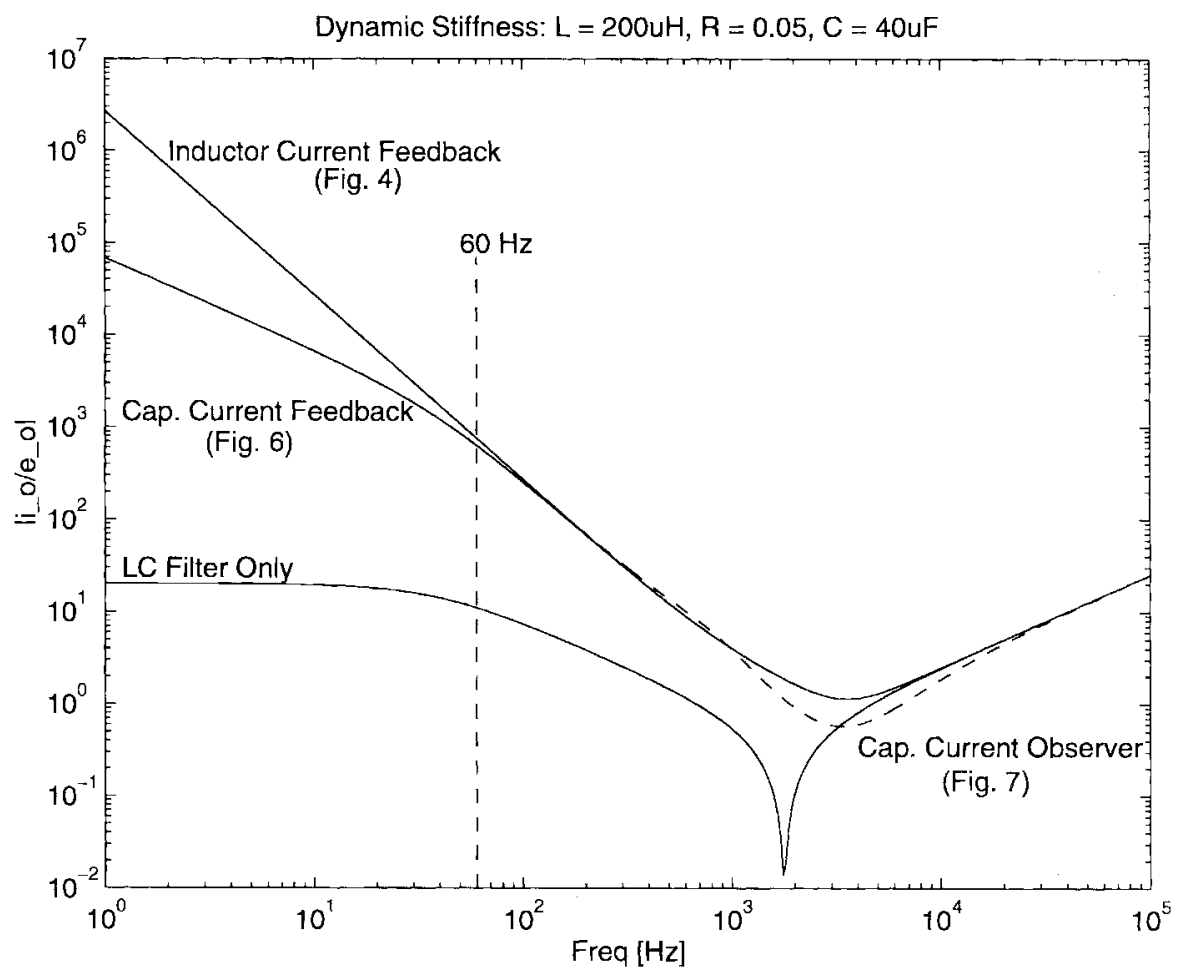

Fig. 8. Dynamic stiffness of controllers.

TABLE I

IGBT INVERTER PARAMETERS

\begin{tabular}{l|c|c}
\hline \multicolumn{1}{c|}{ Parameter } & Value & Units \\
\hline \hline Switching Frequency, $\mathrm{f}_{\mathrm{s}}$ & 20 & $\mathrm{kHz}$ \\
\hline Nominal DC Bus Voltage & 275 & $\mathrm{~V}$ \\
\hline Rated Output Voltage & 120 & $\mathrm{~V}_{\mathrm{rms}}$ \\
\hline Rated Output Frequency & 60 & $\mathrm{~Hz}$ \\
\hline Rated Output Power & 8 & $\mathrm{kVA}$ \\
\hline Rated Output Current & 67 & $\mathrm{~A}_{\mathrm{rms}}$ \\
\hline Filter Inductor, L (Nom.) & 200 & $\mu \mathrm{HH}$ \\
\hline Inductor Resistance, R & 0.050 & $\Omega$ \\
\hline Filter Capacitor, C & 40 & $\mu \mathrm{F}$ \\
\hline
\end{tabular}

zero steady-state errors. Fig. 7 shows the complete controller topology, including the observer. With the exception of the observer, the controller is identical to that of Fig. 6, and the same controller gains $K_{i}, K_{v}$, and $K_{e}$ are used.

The dynamic performance and accuracy of the observer estimate is best evaluated by viewing the observer as a transducer alternative and evaluating its frequency response characteristic. This is given by the following equation, and will be unity at all frequencies only if the parameter estimates, $\hat{L}, \hat{R}$, and $\hat{C}$, are exactly correct:

$$
\frac{\hat{e}_{o}}{e_{o}}=\frac{\hat{e}_{o}}{e_{L R}^{*}} \frac{e_{L R}^{*}}{e_{o}}
$$

or as shown in (6), at the bottom of the page.
The observer characteristic polynomial is the denominator in this equation.

Since robustness is not a concern with observers, the observer gains are chosen based on nominal parameter values to make all eigenvalues equal, corresponding to an observer bandwidth of $2.0 \mathrm{kHz}$, or $0.1 f_{s}$; this bandwidth limits the observer response to switching noise, while still providing adequate overall dynamic stiffness. The resulting gains are summarized in Table II. The effects of parameter variation may be minimized by setting the observer bandwidth as high as possible, although switching frequency components will be corresponding larger in the estimated output voltage derivative.

The observer-based controller dynamic stiffness response function is

$$
\frac{i_{o}}{e_{o}}=\frac{C L s^{3}+\left(C R+G_{o b s} K_{e}\right) s^{2}+K_{v} s+K_{i}}{L s^{2}+R s}
$$

where

$$
G_{o b s}=\frac{\hat{\dot{e}}_{o}}{i_{o}} \frac{i_{o}}{e_{o}} .
$$

The resulting dynamic stiffness transfer function has a sixthorder numerator and a fifth-order denominator.

Fig. 10 depicts the system response with an $8 \mathrm{~kW}$ step load. Note that the output voltage sinewave recovers almost instantly; the transient cannot be noticed on an ordinary $60 \mathrm{~W}$ lightbulb on the same circuit.

$$
\frac{\hat{e}_{o}}{e_{o}}=\frac{C L \hat{L} s^{3}+\left(C \hat{L} R+\hat{L} K_{e o}\right) s^{2}+\left(\hat{R} K_{e o}+\hat{L} K_{v o}\right) s+\hat{L} K_{i o}}{\hat{C} \hat{L}^{2} s^{3}+\left(\hat{C} \hat{L} \hat{R}+\hat{L} K_{e o}\right) s^{2}+\left(\hat{R} K_{e o}+\hat{L} K_{v o}\right) s+\hat{L} K_{i o}}
$$




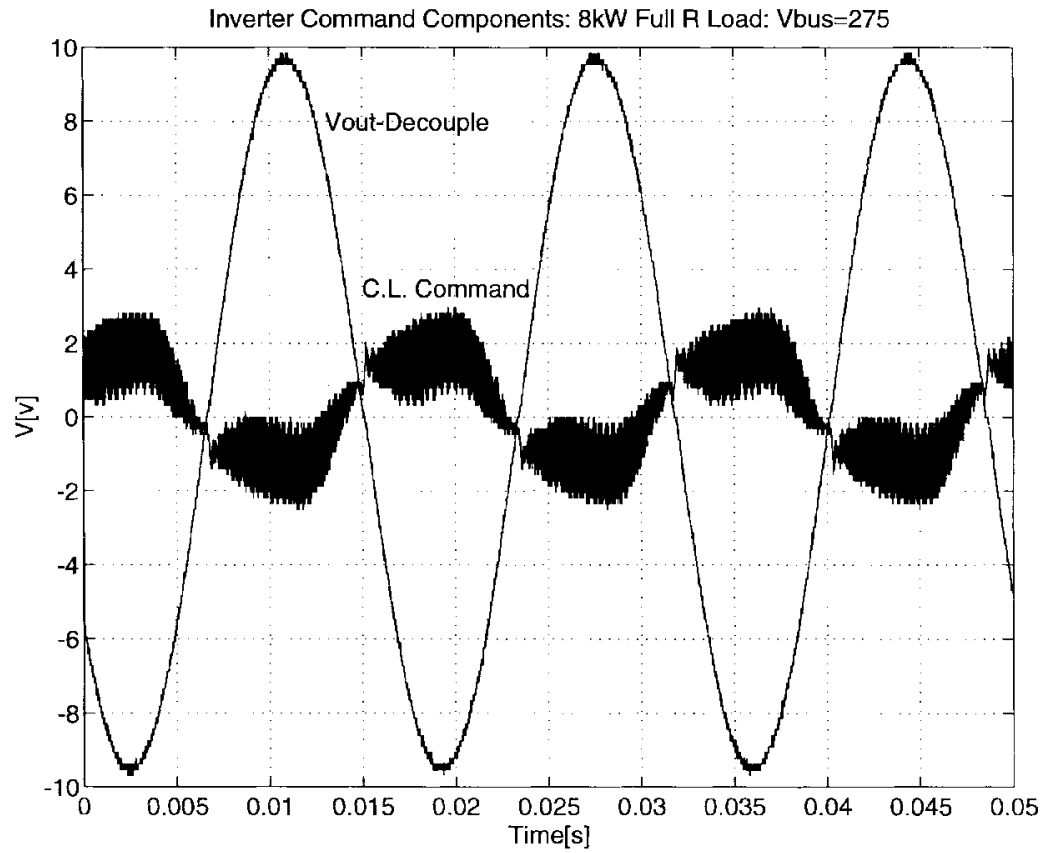

Fig. 9. Inverter command components under full load $(8 \mathrm{~kW})$.

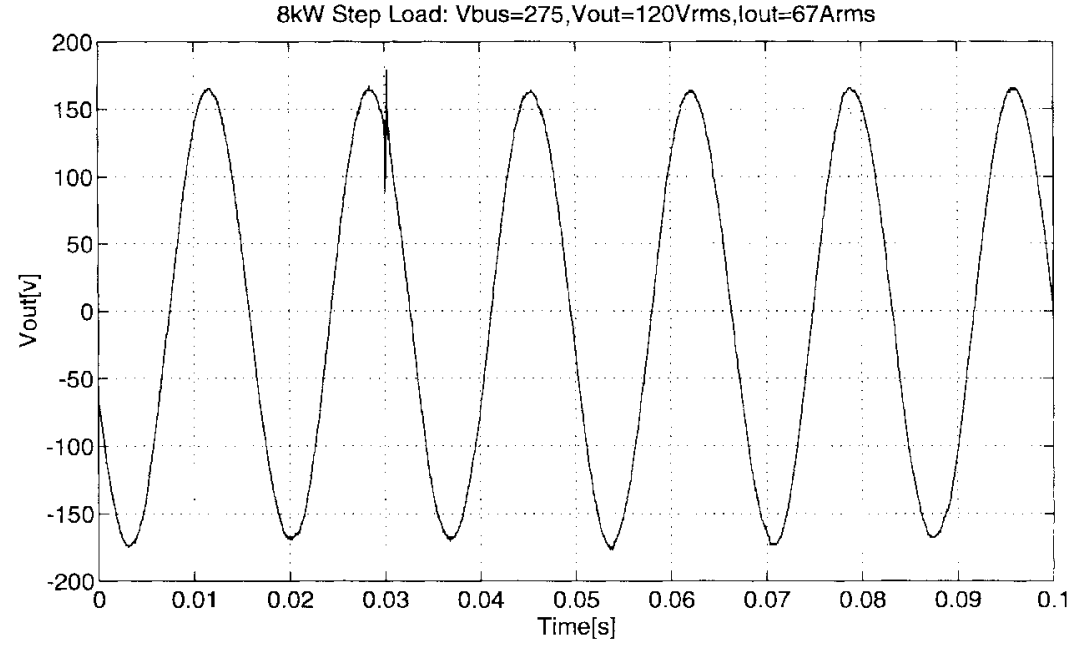

(a)

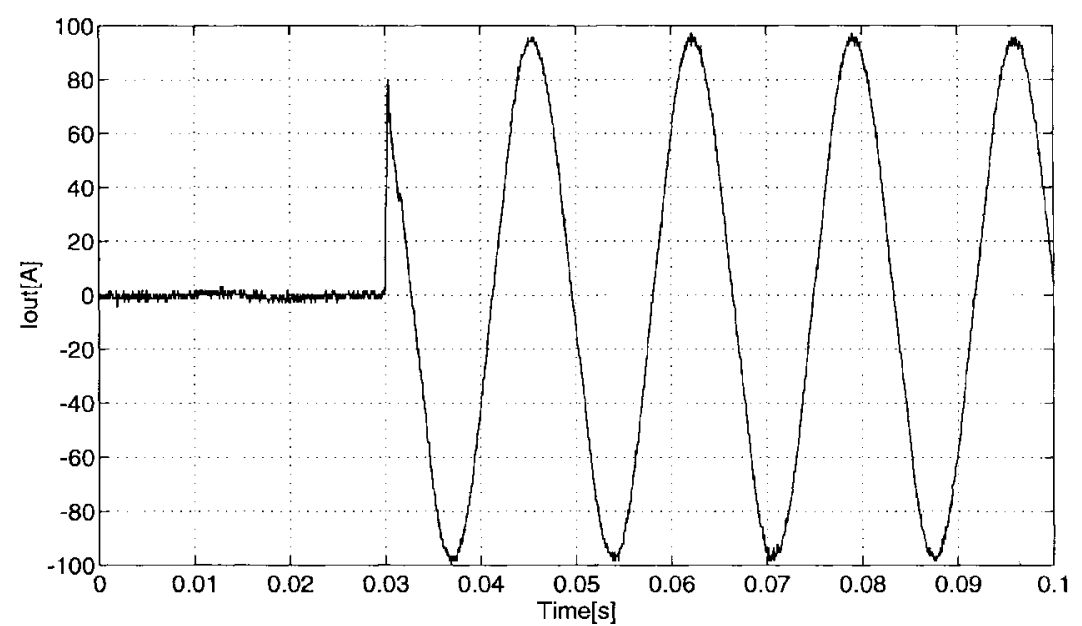

(b)

Fig. 10. 8-kW step load response. (a) Output voltage. (b) Output current. 


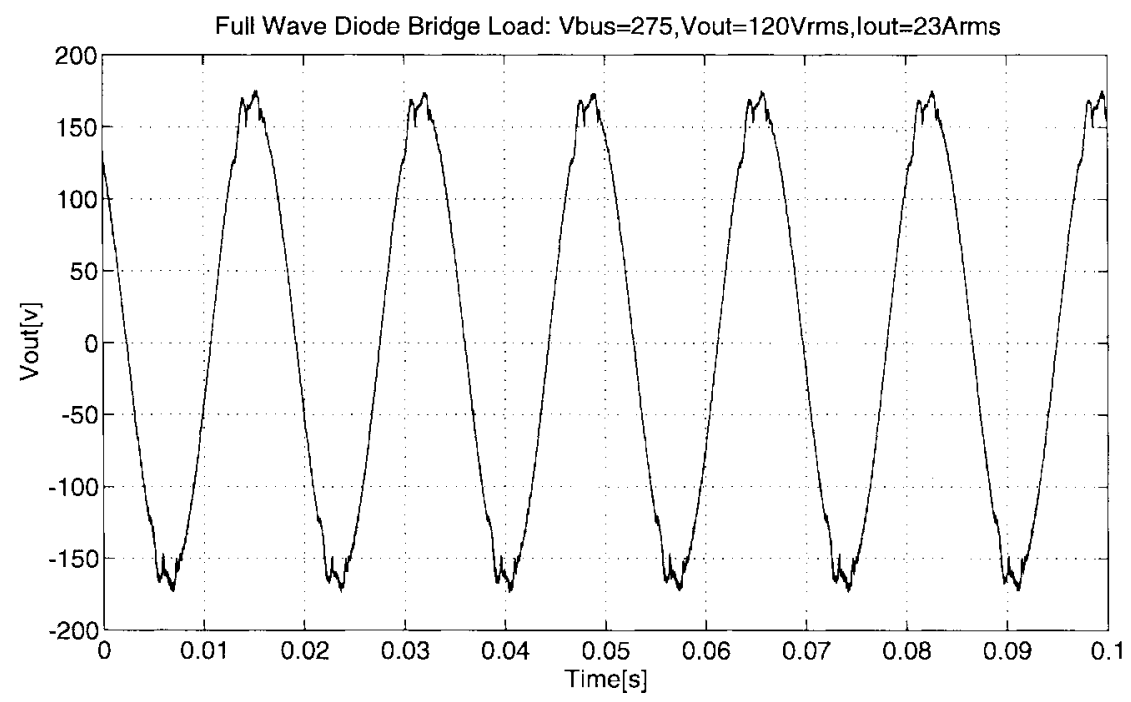

(a)

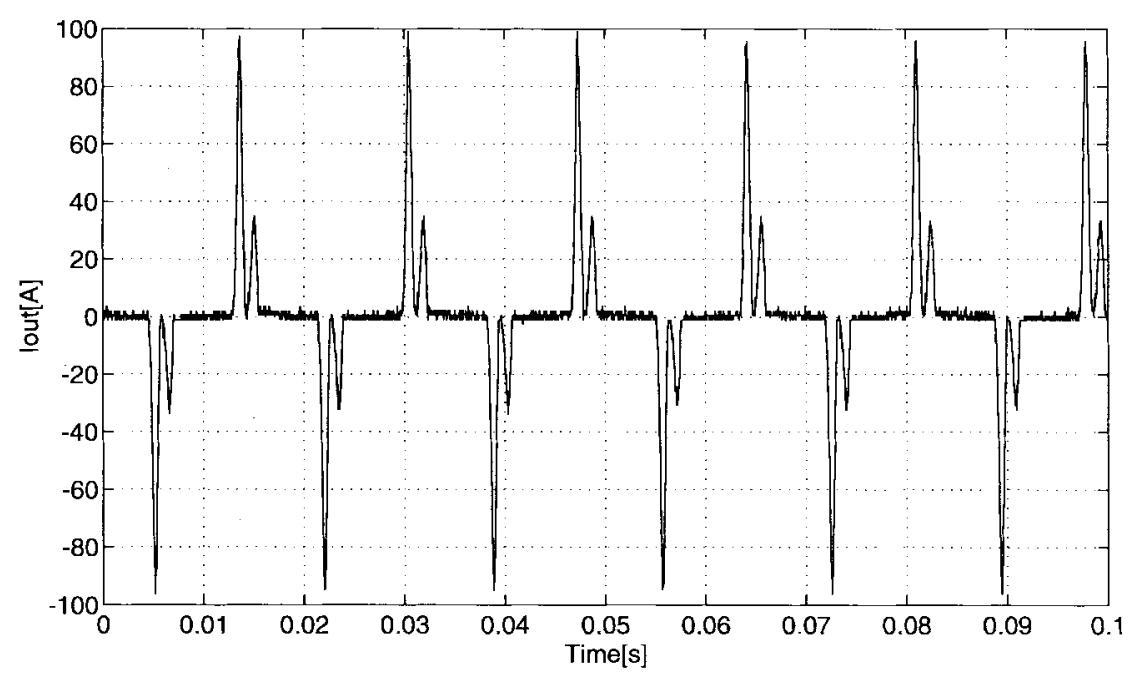

(b)

Fig. 11. FW diode bridge load. (a) Output voltage. (b) Output current.

\section{Disturbance ReJeCtion COMPARISON VIA DYNAMIC STIFFNESS}

The dynamic stiffness of a UPS system is defined as the magnitude of output load current that causes a unit deviation in output voltage magnitude: $\left|I_{o}(s) / E_{o}(s)\right|_{s=j \omega}$. Fig. 8 shows the dynamic stiffness frequency response of the controllers considered earlier. For comparison purposes, all the controllers were evaluated with eigenvalues that corresponded to those implemented in the laboratory. The controller with $d i_{o} / d t$ feedback, Fig. 5, is not included in Fig. 8, as it is infinitely stiff if parameter estimates are correct. With errors in the parameter estimates, the controller stiffness maintains the overall shape of the inductor current feedback curve, but is shifted up by several orders of magnitude.

The disturbance input decoupled controller with $i_{O}$ sensing (Fig. 4) provides superior disturbance rejection compared to the capacitor current controller (Fig. 6) over the low frequency range, but provides negligible improvement for load-current frequency components above $60 \mathrm{~Hz}$, which predominate in most UPS applications. Note that the equivalent $60-\mathrm{Hz}$ output impedance of the controllers is $\approx 2 \mathrm{~m} \Omega$, as compared to the $L C$ filter impedance of $\approx 100 \mathrm{~m} \Omega$.

Over most of the frequency range, the observer-based controller (Fig. 7) provides the same stiffness as the controller with measured capacitor current, but the former suffers decreased performance above the bandwidth of the observer, especially if the $L$ and $C$ parameters vary.

\section{EXPERIMENTAL RESULTS}

The standard capacitor current feedback controller depicted in Fig. 6 (less $e_{i-c f f}$ ) was implemented in the laoratory. Table I lists the specifications of the insulated gate bipolar transistor (IGBT) full-bridge inverter used in the tests. Table II lists the eigenvalues and controller gains for all controllers. 
TABLE II

CONTROLLER GAINS AND BANDwidTHS

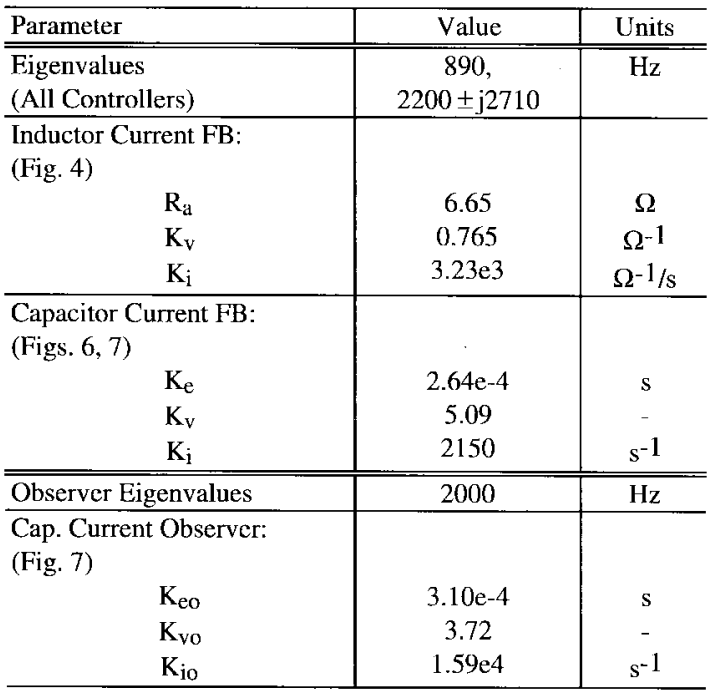

Fig. 9 depicts the relative magnitude of the components making up the inverter command $e_{i}^{*}$ (refer to Fig. 6). Note that the output voltage decoupling makes up $80 \%-90 \%$ of the total inverter command; since the filter inductor impedance is relatively small $\left(X_{L} \approx 75 \mathrm{~m} \Omega @ 60 \mathrm{~Hz}\right)$, the fundamental voltage drop across it is also small. With most of the inverter command being created from the output voltage (i.e., "back-EMF") decoupling, the closed-loop controller gains can be lower and more robust, while still providing excellent disturbance rejection.

To simulate a worst-case loading, a full-wave diode bridge rectifier load was tested. The output of the diode bridge was connected directly to a $1000-\mu \mathrm{F}$ capacitor, with resistive load of $\approx 18 \Omega$. Fig. 11 depicts the results. Note that although the current is drawn in 100-A spikes, the voltage waveform is only slightly distorted. Note additionally that with relatively stiff voltage sources on either side of the diodes, small oscillations in the voltage waveform produce significant current transients. Table III lists the THD of the output voltage under various load conditions.

\section{CONCLUSIONS}

Several UPS inverter control topologies have been presented and evaluated by comparing their dynamic stiffness characteristics. Both filter inductor and filter capacitor current feedback control topologies with full-state command structures have been examined. Various options for physical state feedback decoupling have been presented, each including a "backEMF" decoupling of the output voltage. It has been shown that a controller utilizing load-current derivative feedback can exhibit infinite dynamic stiffness up the dynamic limits of the voltage modulator.

As a low-cost alternative, the filter capacitor current feedback controller exhibits outstanding performance, as can be seen in the experimental results, less than $0.5 \%$ THD with a single-phase full load of $8 \mathrm{~kW}$. Voltage distortion following
TABLE III

Output Voltage THD Performance

\begin{tabular}{c|c|c|c|c}
\hline Load Condition & $\begin{array}{c}\mathrm{i}_{\mathrm{o}} \\
{\left[\mathrm{A}_{\text {rms }}\right]}\end{array}$ & $\begin{array}{c}\mathrm{i}_{\mathrm{o}} \text { Peak } \\
{[\mathrm{A}]}\end{array}$ & $\begin{array}{c}\mathrm{i}_{\mathrm{o}} \text { THD } \\
{[\%]}\end{array}$ & $\begin{array}{c}\mathrm{v}_{\mathrm{o}} \text { THD } \\
{[\%]}\end{array}$ \\
\hline \hline No Load & 0 & 0 & - & 0.35 \\
\hline $\begin{array}{c}\text { Full-Wated Resistive-Load } \\
\begin{array}{c}\text { Fuve Diode Bridge with } \\
\text { C and R-load }\end{array}\end{array}$ & 67 & 95 & - & 0.44 \\
\hline $\begin{array}{c}\text { FWDB Load in parallel with } \\
\text { R-Load }\end{array}$ & 59 & 100 & 160 & 2.77 \\
\hline
\end{tabular}

full power load transients cannot be observed in the intensity output of an average incandescent bulb sharing the same circuit. An observer-based version of this controller is predicted to perform nearly as well, with a further reduction of sensor cost.

\section{REFERENCES}

[1] M. J. Ryan and R. D. Lorenz, "A high-performance sine wave inverter controller with capacitor current feedback and "Back-EMF" decoupling," in Conf. Rec. IEEE-PESC, Atlanta, GA, 1995, pp. 507-513.

[2] N. Abdel-Rahim and J. E. Quaicoe, "A single-phase voltage-source utility interface system for weak AC network applications," in Conf. Rec. IEEE-APEC Conf., Orlando, FL, 1994, pp. 93-99.

[3] S. Jung and Y. Tzou, "Sliding mode control of a closed-loop regulated PWM inverter under large load variations," in Conf. Rec. IEEE-PESC Conf., Seattle, WA, 1993, pp. 616-622.

[4] S. D. Finn, "A high performance inverter technology, architecture and applications," in Conf. Rec. IEEE-APEC Conf., San Diego, CA, 1993, pp. 556-560

[5] N. R. Zargari, P. D. Ziogas, and G. Joos, "A two switch high performance current regulated DC/AC converter module," in Proc. IEEE-IAS Annu. Meeting, Seattle, WA, 1990, pp. 929-934.

[6] S. Vukosavic, L. Peric, E. Levi, and V. Vuckovic, "Reduction of the output impedance of PWM inverters for uninterruptible power supplies," in Conf. Rec. IEEE-PESC Conf., San Antonio, TX, 1990, pp. 757-762.

[7] G. Venkataramanan, D. M. Divan, and T. M. Jahns, "Discrete pulse modulation strategies for high-frequency inverter systems," in Rec. IEEE-PESC Conf., Milwaukee, WI, 1989, pp. 1013-1020.

[8] A. Skjellnes, G. Snilsbert, and E. Munchow, "Matching a UPS to the computer market," presented at the IEEE-INTELEC, Florence, Italy, paper no. 19.6, 1989.

[9] M. Carpita, M. Mazzucchelli, S. Savio, and G. Sciutto, "A new PWM control system for UPS using hysteresis comparator," in Proc. IEEE IAS Annu. Meeting, Atlanta, GA, 1987, pp. 749-754.

[10] T. Haneyoshi, A. Kawamura, and R. G. Hoft, "Waveform compensation of PWM inverter with cyclic fluctuating loads," in Proc. IEEE IAS Annu. Meeting, Denver, CO, 1986, pp. 744-751.

[11] T. Kawabata et al., "Chargerless UPS using multi-functional BIMOS inverter-Sinusoidal voltage waveform inverter with current minor loop," in Proc. IEEE IAS Annu. Meeting, Denver, CO, 1986, pp. 513-520.

[12] A. Kawamura and R. G. Hoft, "Instantaneous feedback controlled PWM inverter with adaptive hysteresis," IEEE Trans. Ind. Applicat., vol. IA-20, pp. 769-775, July/Aug. 1984.

[13] D. G. Luenberger, "An introduction to observers," IEEE Trans. Automat. Contr., vol. AC-16, pp. 596-602, Nov./Dec. 1971.

[14] R. D. Lorenz, T. A. Lipo, and D. W. Novotny, "Motion control using induction motors," Proc. IEEE, vol. 82, pp. 1215-1240, Aug. 1994.

[15] R. D. Lorenz, "Microprocessor control of motor drives and power converters," IEEE Tutorial Course Note Book from 1991-1993 IEEEIAS Annu. Meetings, ch. 4.

[16] R. D. Lorenz and K. VanPatten, "High resolution velocity estimation," IEEE Trans. Ind. Applicat., vol. 27, pp. 701-708, July/Aug. 1991. 


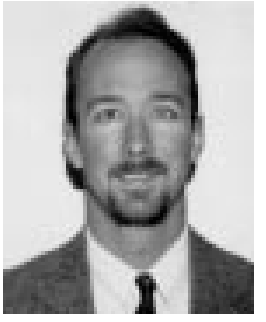

Michael J. Ryan received the B.S. degree in electrical engineering from the University of Connecticut, Storrs, in 1988, and the M.E. degree from Rensselaer Polytechnic Institute, Troy, NY, in 1992, with a concentration in robotics and automation. He is currently pursuing the Ph.D. degree in electrical engineering at the University of Wisconsin, Madison, where his research involves power electronic inverters and their control.

He has had a wide range of industrial experience with positions at General Electric, Hamilton Standard, and Otis Elevator. His work has included power electronic converters for brush and brushless dc motors, real-time micro-processor control and programming, path-planning, kinematics, and control for multiaxis winding machines, and soft-switching design of resonant inverters for ac traction motor applications. While at the University of Wisconsin, he has worked in the Wisconsin Power Electronics Research Center (WisPERC) on projects including $\mathrm{dc}-\mathrm{dc}$ converters, variable speed generators, and UPS inverter design. In addition, he has worked with the school's Hybrid Electric Vehicle Group on vehicles that have won titles at several national competitions.

Mr. Ryan is a member of the IEEE Industry Applications and Power Electronics Societies.

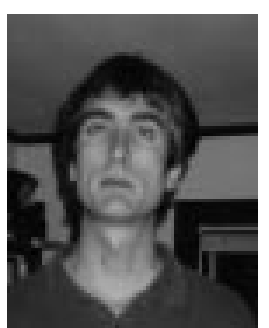

William E. Brumsickle received the B.S. degree in physics from the University of Washington, Seattle, in 1982, and the M.S. degree in electrical engineering from the University of Wisconsin, Madison, in 1995, where he is currently pursuing the Ph.D. degree.

From 1986 to 1992, he worked for Enerpro Inc. Goleta, CA, mainly as Applications Engineer for thyristor phase control applications. Since 1993, he has been a Research Assistant at the Wisconsin Power Electronics Research Center (WisPERC), where his work has included development of a high-efficiency dc/dc converter for battery-powered stand-alone and UPS inverters, investigations of highpower inverter and UPS topologies, and analysis of power electronic building block (PEBB)-based systems. His present research interests focus on IGBTbased soft-switching inverters and motor drives for multimegawatt systems.

Mr. Brumsickle is a member of the Industry Applications and Power Electronics Societies.

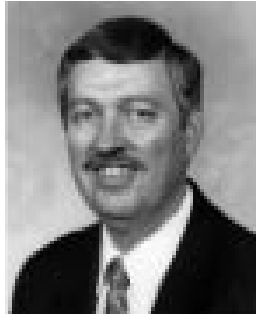

Robert D. Lorenz (S'83-M'84-SM'91) received the B.S., M.S., and Ph.D. degrees from the University of Wisconsin, Madison, in 1969, 1970, and 1984, respectively.

Since 1984 , he has been a member of the faculty of the University of Wisconsin, Madison, where he currently is a Professor of mechanical engineering and of electrical and computer engineering. In this position, he acts as Associate Director of the Wisconsin Electric Machines and Power Electronics Consortium and as Co-Director of the Advanced Automation and Robotics Consortium. He is also an active consultant to many organizations. He was a Visiting Research Professor in the Electrical Drives Group of the Catholic University of Leuven, Leuven, Belgium, and in the Electrical Drives Institute of the Technical University of Aachen, West Germany, in the summer of 1989 and the summers of 1987, 1991, and 1995, respectively. From 1969 to 1970, he researched his Master's thesis at the Technical University of Aachen.. From 1972 to 1982, he was a member of the research staff at the Gleason Works, Rochester, NY. His current research interests include sensor-integrated electromagnetic actuator technologies, realtime digital signal processing and estimation techniques, and ac drive and high-precision machine control technologies.

Dr. Lorenz is currently Chair of the IAS Awards Department and a member of the Industrial Automation and Control Committee, the Electrical Machines Committee, and the Industrial Power Converter Committee, as well as being past Chairman of the IAS Industrial Drives Committee. He is a Registered Professional Engineer in the States of New York and Wisconsin and is a member of the ASME, ISA, and SPIE. 